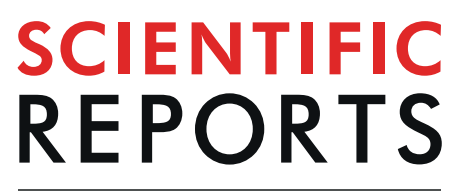

natureresearch

Check for updates

\title{
Woody Plant Encroachment has a Larger Impact than Climate Change on Dryland Water Budgets
}

\author{
Adam P. Schreiner-McGraw ${ }^{1,2}{ }^{\square}$, Enrique R. Vivoni ${ }^{1,3}{ }^{3}$, Hoori Ajami ${ }^{2}$, Osvaldo E. Sala ${ }^{4,5,6}$, \\ Heather L. Throop ${ }^{1,4}$ \& Debra P. C. Peters ${ }^{7}$
}

Woody plant encroachment (WPE) into grasslands is a global phenomenon that is associated with land degradation via xerification, which replaces grasses with shrubs and bare soil patches. It remains uncertain how the global processes of WPE and climate change may combine to impact water availability for ecosystems. Using a process-based model constrained by watershed observations, our results suggest that both xerification and climate change augment groundwater recharge by increasing channel transmission losses at the expense of plant available water. Conversion from grasslands to shrublands without creating additional bare soil, however, reduces transmission losses. Model simulations considering both WPE and climate change are used to assess their relative roles in a late $21^{\text {st }}$ century condition. Results indicate that changes in focused channel recharge are determined primarily by the WPE pathway. As a result, WPE should be given consideration when assessing the vulnerability of groundwater aquifers to climate change.

Global drylands covering nearly $40 \%$ of the Earth's land surface have been dramatically transformed by woody plant encroachment (WPE) ${ }^{1-4}$. Managed grazing is the predominant use of drylands, making it the single most extensive form of land use on the planet ${ }^{1}$. As such, WPE into grasslands is often considered a negative outcome since it may reduce forage production for livestock ${ }^{5}$ and decrease habitat for native species ${ }^{6}$. As shrubs become dominant in a dryland ecosystem, processes in the water and energy budgets are affected ${ }^{7-9}$, including groundwater recharge ${ }^{10}$. Most prior observational ${ }^{11,12}$ and modeling ${ }^{13}$ efforts indicate that WPE reduces diffuse vertical recharge due to water uptake by deeply rooted woody plants ${ }^{12,14}$. However, these cases have focused on flat areas that lack topographic effects on water transport. Where terrain controls are important ${ }^{15}$, WPE could potentially have local and downstream consequences on both vertical and lateral water exchanges. Nevertheless, little evidence is available on downstream consequences of WPE within interconnected hillslope and channel systems ${ }^{16}$, even though many arid landscapes consist of these topographic features.

In addition to WPE, directional changes in climate are expected to impact water budgets in drylands ${ }^{17}$. Prior studies in these regions predict drying caused by increased temperatures and higher evapotranspiration $(E T)^{18-20}$, in some cases with decreases in precipitation ${ }^{21,22}$. In addition to directional changes in precipitation and temperature, changes to precipitation frequency, intensity, and seasonal distributions are expected ${ }^{23}$. Recent work has shown that increases in precipitation variability are more important than changes to the mean annual precipitation in impacting groundwater recharge in dryland playa lakes $^{24}$. Prior observations and model simulations also suggest significant climate change impacts of extreme precipitation events $s^{25,26}$. These impacts are critical because extreme storm events with a high magnitude or intensity can generate streamflow and channel transmission losses. For instance, channel losses contribute up to $40 \%$ of recharge to arid and semiarid aquifers ${ }^{27}$, and these losses are commonly used as proxies for recharge ${ }^{28}$. While conceptual models of the hydrologic impact of WPE and climate change have been proposed ${ }^{7}$, studies on their combined effects on channel transmission losses are lacking. Indeed, it is unknown if WPE and climate change will interact in a linearly additive manner or in a nonlinear way to affect groundwater recharge in drylands.

\footnotetext{
${ }^{1}$ School of Earth and Space Exploration, Arizona State University, Tempe, AZ, 85287, USA. ${ }^{2}$ Department of Environmental Sciences, University of California, Riverside, CA, 92587, USA. ${ }^{3}$ School of Sustainable Engineering and the Built Environment, Arizona State University, Tempe, AZ, 85287, USA. ${ }^{4}$ School of Life Sciences, Arizona State University, Tempe, AZ, 85287, USA. ${ }^{5}$ Global Drylands Center, Arizona State University, Tempe, AZ, 85287, USA. ${ }^{6}$ School of Sustainability, Arizona State University, Tempe, AZ, 85287, USA. ${ }^{7}$ USDA-ARS, Las Cruces, New Mexico, 88001, USA. ${ }^{\circledR}$ e-mail: adampschreiner@gmail.com
} 
(a)

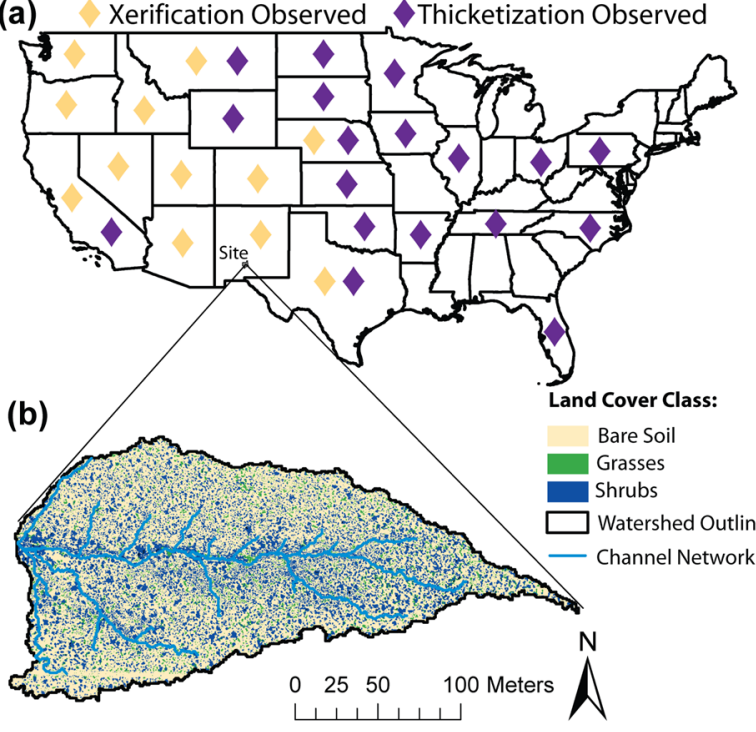

(c) Xerification Pathway
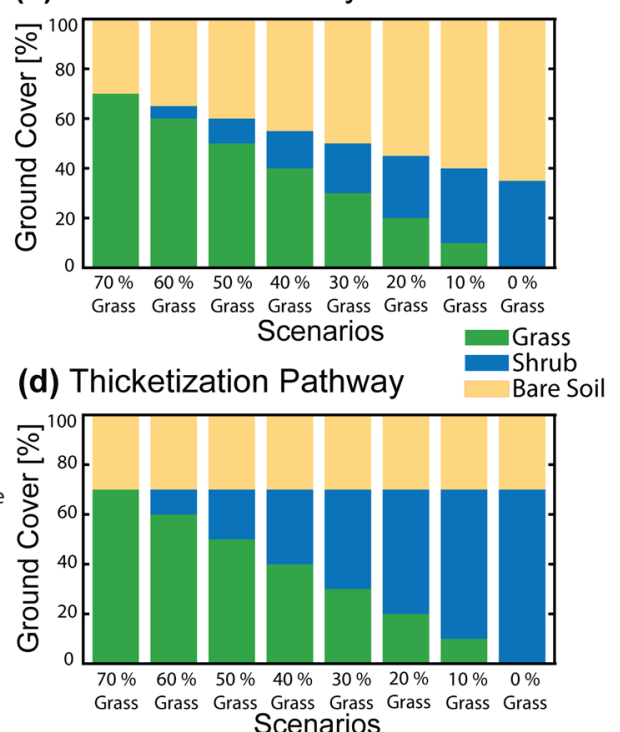

Figure 1. Model scenarios in the context of continental scale WPE. (a) Study site location along with WPE pathways in the United States. Diamonds indicate states where woody plant encroachment, via xerification (yellow) or thicketization (purple), has been observed ${ }^{27}$. (b) Current spatial pattern of grasses, shrubs, and bare soils (2013) at the watershed study site. Stacked bar plots illustrate WPE model scenarios for the xerification pathway (c) and the thicketization pathway (d).

In the U.S., WPE occurs via two pathways (Fig. 1a): 'xerification' is where grass loss associated with WPE leads to an increase in bare soil cover, while 'thicketization' involves the replacement of grasses by shrubs without a simultaneous increase in bare soil ${ }^{29}$. In dry environments where water resources are limited, grassland plants tend to be smaller and more tightly spaced together than do shrublands. Gaps between shrubs allow resource removal by wind ${ }^{30}$ and water ${ }^{31}$ transport, which increases the bare soil coverage. Mean annual precipitation is a good predictor for the occurrence of each pathway, with drier areas ( $<400 \mathrm{~mm}$ per year) in the western U.S. undergoing xerification ${ }^{32,33}$, while wetter sites in the central and eastern U.S. have experienced primarily thicketization $^{34,35}$. This distinction is important as these pathways directly affect the connectivity of surface flow over bare soil patches, and the lateral subsurface water movement on hillslopes ${ }^{36}$, which in turn impact focused recharge in downstream channels ${ }^{37,38}$. Since channel losses depend on hillslope processes affected by plants, a modeling approach that can account for both terrain and vegetation patch effects on hydrologic connectivity is needed. Similar pathways of WPE can be found globally ${ }^{39}$ and have been identified in Africa ${ }^{40}$, South America ${ }^{41}$, and China ${ }^{42}$, although the precipitation thresholds indicating which pathway is more likely are not clear.

We applied a distributed, process-based ecohydrological model to determine the hydrologic impacts of WPE and climate change. The investigation was performed using data from a small, densely instrumented watershed (4.6 ha) in the Chihuahuan Desert (Fig. 1b) where historical WPE has been well documented ${ }^{43-45}$. We conducted a series of simulation scenarios using observed meteorological data over a 6.25-year period (using all available data) to quantify impacts of xerification (Fig. 1c) and thicketization (Fig. 1d) pathways by varying the percentages of shrub, grass, and bare soil cover. We then used a stochastic downscaling approach to construct synthetic time series of meteorological forcings based on historical (1990-2005) and late century (2085-2100) conditions projected from three general circulation models (GCMs) and one greenhouse gas emissions scenario (RCP 8.5). Our analysis focuses on the consequences of the combined effects of WPE and climate change on the evapotranspiration and channel transmission losses that form the major parts of the dryland water budget.

With this framework, we address the following questions about the conversion of grasslands to shrublands: (1) What are the impacts of woody plant encroachment on the dryland water budget? (2) Do varying WPE pathways lead to different water budget components?, and (3) What are the relative roles of WPE and projected climate conditions on channel transmission losses at the end of the $21^{\text {st }}$ century?

Diverging effects of WPE on water budget components. Simulations using the 6.25-year observed forcings (Fig. S1) with a calibrated model (see Methods) show that WPE via the xerification pathway increased focused recharge in channel features during summer months with high precipitation (Fig. 2a). While WPE does not affect the precipitation threshold necessary for recharge $(40 \mathrm{~mm} / \mathrm{month}$ in this system) among various xerification scenarios, the annual ratio of transmission losses to precipitation $\left(T_{L} / P\right)$ increases with lower grass cover, equivalent to $+13 \mathrm{~mm}$ per year or $+29 \%$ for the lowest grass cover scenario relative to an initial grassland. Due to the higher bare soil cover during xerification, larger amounts of infiltration-excess overland flow from hillslopes reach the channel network ${ }^{46}$, augmenting channel transmission losses that lead to focused recharge ${ }^{37}$. This result is consistent with prior studies showing a reduction of infiltration with increases in bare soil ${ }^{47}$ at both the plot 

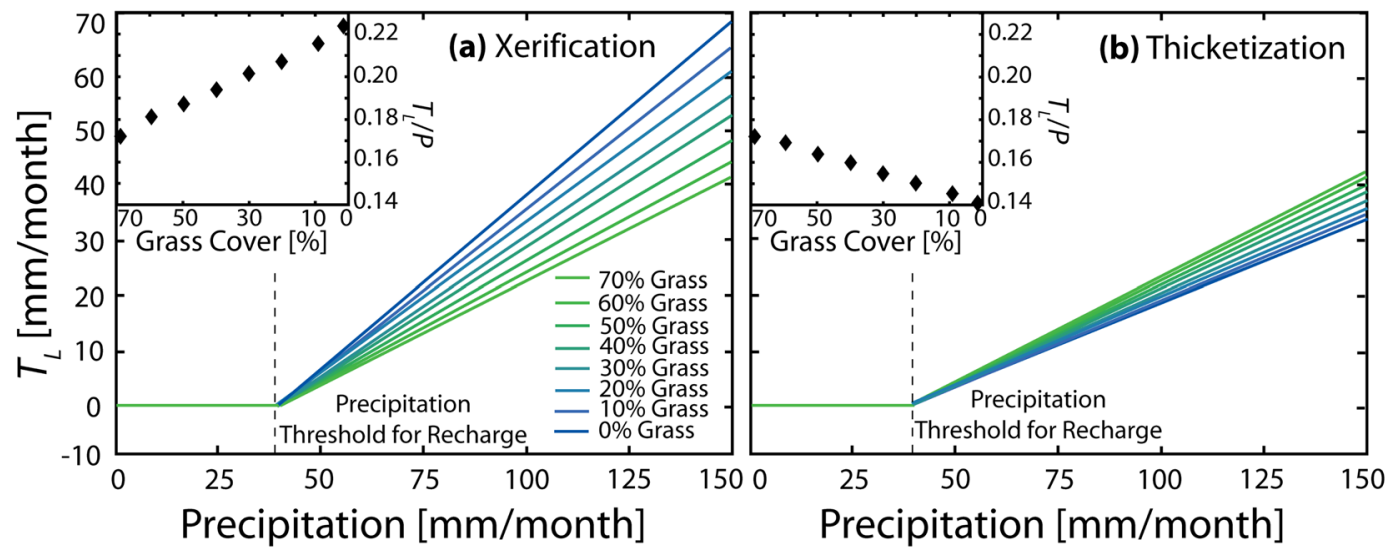

Figure 2. Impacts of two woody plant encroachment pathways on transmission losses. Relation between monthly transmission losses $\left(T_{L}\right)$ and precipitation $(P)$ for $(\mathbf{a})$ xerification and $(\mathbf{b})$ thicketization pathways. Insets display annual $T_{L} / P$ relation with percent grass cover $(\%)$.

\begin{tabular}{|l|l|l|l|l|l|l|l|}
\hline Scenario & Grass Cover & $\boldsymbol{P}[\mathbf{m m} / \mathbf{y r}]$ & $\boldsymbol{E}[\mathbf{m m} / \mathbf{y r}]$ & $\mathbf{Q}[\mathbf{m m} / \mathbf{y r}]$ & $\boldsymbol{T}_{L}[\mathbf{m m} / \mathbf{y r}]$ & $\mathbf{M e a n} \Theta[\mathbf{m m}]$ & $\boldsymbol{T}_{\mathbf{L}} / \boldsymbol{P}[-]$ \\
\hline \multirow{5}{*}{ Xerification Pathway } & $70 \%$ & 271 & 220 & 3 & 47 & 19.1 & 0.173 \\
\cline { 2 - 8 } & $60 \%$ & 271 & 215 & 6 & 49 & 18.9 & 0.181 \\
\cline { 2 - 8 } & $50 \%$ & 271 & 211 & 8 & 51 & 18.8 & 0.188 \\
\cline { 2 - 8 } & $40 \%$ & 271 & 207 & 10 & 53 & 18.7 & 0.195 \\
\cline { 2 - 8 } & $30 \%$ & 271 & 205 & 11 & 55 & 18.5 & 0.202 \\
\cline { 2 - 8 } & $20 \%$ & 271 & 203 & 11 & 57 & 18.4 & 0.209 \\
\cline { 2 - 8 } & $10 \%$ & 271 & 201 & 10 & 59 & 18.2 & 0.216 \\
\cline { 2 - 8 } & $0 \%$ & 271 & 201 & 9 & 61 & 18.0 & 0.223 \\
\hline \multirow{5}{*}{ Thicketization Pathway } & 271 & 220 & 3 & 47 & 19.1 & 0.173 \\
\cline { 2 - 8 } & $60 \%$ & 271 & 221 & 3 & 46 & 19.0 & 0.169 \\
\cline { 2 - 8 } & $50 \%$ & 271 & 223 & 3 & 44 & 19.0 & 0.164 \\
\cline { 2 - 8 } & $40 \%$ & 271 & 224 & 3 & 43 & 18.9 & 0.159 \\
\cline { 2 - 8 } & $30 \%$ & 271 & 225 & 3 & 42 & 18.9 & 0.154 \\
\cline { 2 - 7 } & $20 \%$ & 271 & 227 & 3 & 40 & 18.7 & 0.149 \\
\cline { 2 - 7 } & $10 \%$ & 271 & 228 & 3 & 40 & 18.7 & 0.146 \\
\cline { 2 - 7 } & $0 \%$ & 271 & 230 & 2 & 38 & 18.6 & 0.142 \\
\hline
\end{tabular}

Table 1. Annual water budget components for xerification and thicketization pathways using observed meteorological forcing. Water budget variables: $P$ is the precipitation, $E T$ is evapotranspiration, $Q$ is streamflow at the watershed outlet, and $T_{L}$ is transmission losses. The mean soil moisture (Mean $\Theta$ ) for the 6.25-year period is also presented as interannual changes in soil water storage are negligible.

and field scales ${ }^{48}$ as well as increases in the hydrologic connectivity of hillslopes and channel systems during xerification ${ }^{49,50}$.

While increases in focused recharge caused by xerification are linear, other water budget components exhibit nonlinearities with a reduction in grass cover (Table 1). Reductions in ET are due to the lower soil infiltration caused by higher bare soil, yielding large declines of annual ET/P from 81 to $74 \%$. In dryland settings, ET is water limited, such that this trend reflects a decrease in plant available water with increasing $T_{L}$. Indeed, the high aridity in the study watershed results in all of the $P$ that infiltrates into the soil being used for $E T$, irrespective of the type of plant. As a result, changes to watershed ET reflect changes to the physical structure of the watershed that impact infiltration of $P$ into the soil. It is noteworthy that reductions in $E T$ asymptote towards $200 \mathrm{~mm}$ per year in the xerification pathway for the lowest grass cover. This asymptote is caused by the increase in ET from shrub patches as the total vegetation cover decreases (Fig. S2). Since bare soil patches do not transpire soil water, their expansion with xerification provides more opportunity for overland flow generation in bare soil patches and lateral soil water redistribution to shrub locations.

By increasing infiltration-excess runoff, WPE via the xerification pathway also results in a nonlinear increase in streamflow, $Q$ (Table 1 ). Though annual $Q / P$ are typically low (1 to $4 \%$ ), a notable maximum in streamflow is observed for grass cover between 20 and $30 \%$ for the xerification pathway. Since the partitioning between $Q$ and $T_{L}$ is controlled by the interaction between hillslope runoff and the initial channel infiltration capacity ${ }^{46,51}$, this nonlinearity is explained by the variation of hydrograph properties with changes in grass cover. Low grass cover increases the hillslope flow connectivity which results in more overland flow reaching the dry ephemeral channel 
during a transient period when capillary forces increase infiltration rates (see Methods). This results in higher $T_{L}$ and lower streamflow for the lowest grass cover cases.

Since WPE does not result in an increase in bare soil along the thicketization pathway, an opposite response to the xerification case is noted. Indeed, $T_{L} / P$ shows a linear decrease as grass cover decreases (Fig. $2 \mathrm{~b}$, Table 1 ). This reduction is caused by two mechanisms that increase ET/P from 81 to $85 \%$ : increased shrub canopy interception of precipitation and increased soil infiltration underneath shrubs as compared to grasses ${ }^{52,53}$. Canopy interception capacity in shrub areas increases by $64 \%$ up to a threshold of $0.65 \mathrm{~mm}$ due to the higher leaf area index of shrubs ${ }^{54}$, while soil infiltration increases by $66 \%$ due to the higher surface hydraulic conductivity underneath shrubs as compared to grasses (Table S1). WPE along the thicketization pathway also reduces streamflow from $Q / P$ of $1 \%$ to $0.8 \%$, though the sensitivity is quite low. While these effects also occur for the xerification pathway, the impact of expanding bare soil cover on runoff production overwhelms other shrub-induced mechanisms, leading to the diverging impacts of the two different encroachment pathways on evapotranspiration and channel transmissions losses.

Non-stationarity of hydrologic impact of WPE with climate change. We simulated vegetation cover conditions for the final states of the WPE pathways (Fig. 1c,d) and an initial grassland state (70\% grass, $30 \%$ bare soil) for late $21^{\text {st }}$-century climate conditions (2085-2100) and compared these to a historical climate period parameterized with NLDAS-2 (Fig. S3, Methods). Overall, annual changes in channel transmission losses show that WPE has a stronger impact on dryland water budgets than the worst-case climate change conditions (late-century, RCP 8.5) explored here. As described previously, annual differences in $T_{L}$ between a historic grassland and final shrub states show diverging outcomes under the two pathways (Fig. 3a). These effects are larger than the climate change impact on a grassland for the three GCMs. Indeed, the WPE cases show a greater sensitivity than the possible future impacts of climate change alone. When the effects are combined (Fig. $3 \mathrm{~b}$ ), the annual change in $T_{L}$ is not a linearly additive process and the directionality of the future changes are determined almost entirely by the WPE pathway, rather than the magnitude of the imposed climate change signal.

To further explore this outcome, Fig. $3 \mathrm{c}$ shows how the WPE pathways will affect $T_{L}$ for the projected climate conditions at late-century. While the general patterns discussed previously still hold, the sensitivity to WPE varies considerably as compared to the historical period (Fig. 3b). This demonstrates that there is an embedded non-stationarity imposed by climate change on the hydrologic response to WPE for both pathways. Specific changes to $T_{L}$ for each shrubland state depend on the climate-induced changes in precipitation amount and patterns ${ }^{55}$. For instance, the CSIRO projected climate (reduced total precipitation, increased precipitation intensity) shows large impacts to the annual $T_{L}$ changes, with a reduced sensitivity for the xerification, and increased sensitivity for the thicketization pathways, as compared to the historical climate. The non-stationarity in climate can be linked directly to precipitation properties (Table S2) that determine whether WPE will yield greater focused recharge. By comparing the projected changes to climate with Fig. 3, it is noted that in systems with high bare soil, the CSIRO model with a high average storm intensity and low annual precipitation results in the most $T_{L}$. Along the thicketization pathway, the HadGEM2-ES model predicts the most $T_{L}$ due to its higher annual precipitation which overcomes the canopy interception from the higher amount of shrub cover. Interannual variability in the $T_{L}$ representing a range of potential climate and WPE impacts demonstrates that WPE largely determines the directionality of changes (Fig. S4). Changes to individual precipitation properties, such as an increase in the average daily storm size or the average annual precipitation, can have a larger impact than WPE on transmission losses (Fig. S5). GCMs do not predict such drastic changes to precipitation properties, however, so when the range of likely changes to precipitation properties is considered WPE is shown to be the primary driver of changes to $T_{L}$ (Fig. S6).

Implications of WPE for groundwater sustainability. Woody-plant encroachment into grasslands is often considered a negative outcome and associated with land degradation. Nevertheless, our modeling results illustrate that xerification in a landscape leading to high cover of bare soil can yield increased $T_{L}$, leading to focused groundwater recharge. At the same time, plant available water is reduced, providing an advantage to shrubs in their competition with grasses ${ }^{56,57}$ and yielding a positive feedback loop that promotes further WPE and focused recharge. In contrast, the thicketization pathway decreases channel losses by increasing hillslope infiltration and evapotranspiration, suggesting that woody plant encroachment in humid regions will not enhance groundwater recharge. Some studies have hypothesized that increases to streamflow in upland systems may result in supplemental water deliveries to downstream ecosystems ${ }^{16}$. Our results suggest that although both WPE and climate change may increase runoff production on hillslopes, this runoff is absorbed in first order channels and does not subsidize downstream ecosystems.

Under a changing climate, the impact of WPE on the dryland water budget is more important than the climate change signal. However, a climate-induced non-stationarity in the hydrologic response emerges for each WPE pathway. For the xerification pathway, water budget components are highly sensitive to changes in extreme precipitation events, whereas the thicketization pathway is most sensitive to changes in total precipitation. We illustrate how this global phenomenon can affect groundwater aquifers through positive (xerification) or negative (thicketization) feedbacks linked to ecohydrological processes. Given that groundwater is the major freshwater resource in many drylands, land managers should consider how woody plant encroachment could affect aquifer sustainability. Because groundwater recharge is potentially more strongly linked to the vegetation state than climate change, WPE should become part of the discourse about management of dryland aquifers in the future. 
(a) Independent Effects

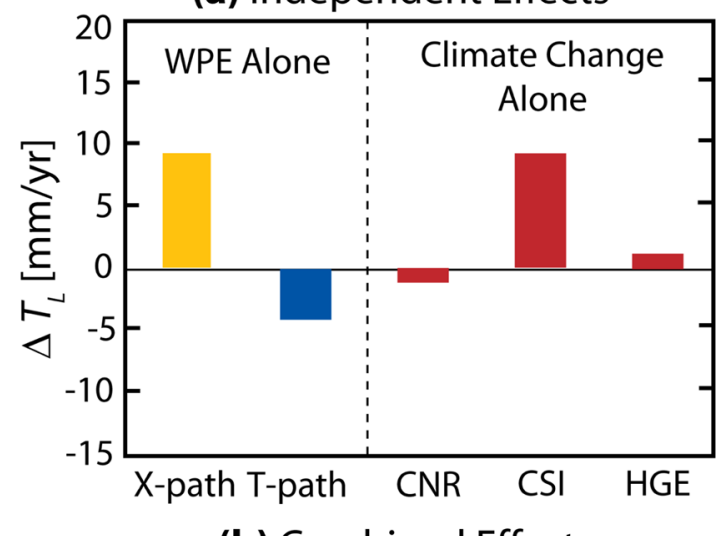

(b) Combined Effects
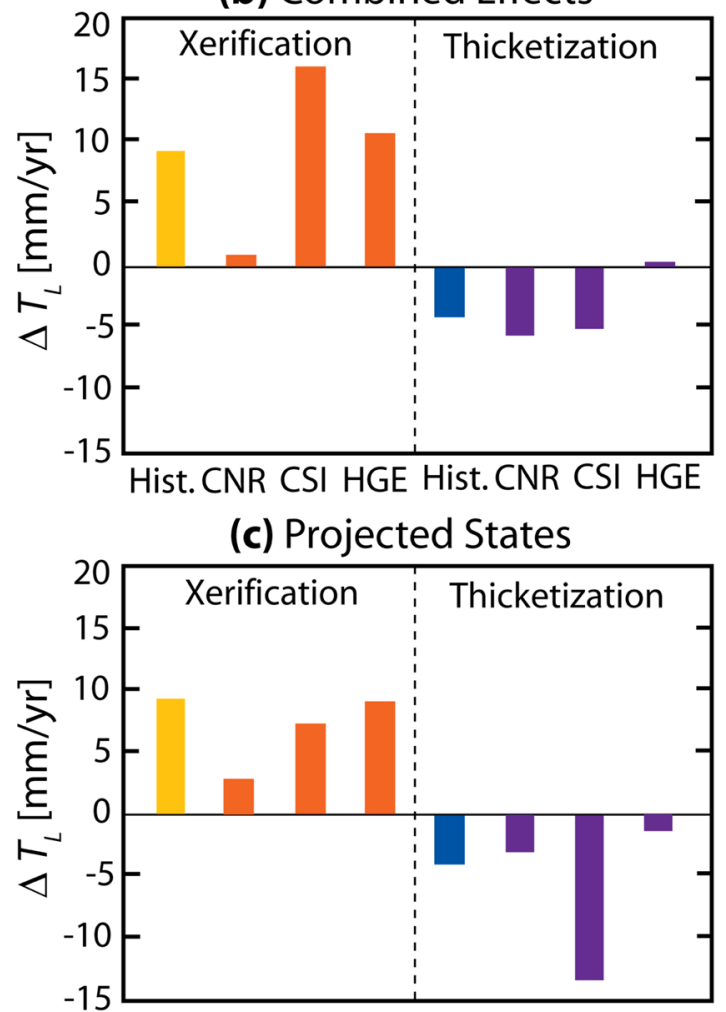

Hist. CNR CSI HGE Hist. CNR CSI HGE

Figure 3. Combined impacts of climate change and WPE on transmission losses. (a) The difference in the average annual $T_{L}$ between a historical grassland and end-member shrubland states forced with historical climate (left) and grassland forced with climate change forcings (right). The X-path is the xerification pathway and the T-path is the thicketization pathway. (b) The difference in the average annual $T_{L}$ between a historical grassland and two shrubland states forced with a historical climate based on NLDAS-2 data ('Hist.') or one of 3 climate change projections, CNRM-CM5 ('CNR'), CSIRO Mk.3.6.0 ('CSI'), or HadGEM2-ES ('HGE'). (c) The difference in the average annual $T_{L}$ between shrubland and grassland when both vegetation states use the same meteorological forcings for historical conditions ('Hist.') or one of the 3 climate change projections.

\section{Methods}

Ecohydrological Process Modeling. Numerical simulations were performed using the TIN-based Realtime Integrated Basin Simulator, RRIBS $^{58,59}$, a fully-distributed, physically-based ecohydrological model. The tRIBS framework captures high-resolution topography, soil type, vegetation, and meteorological conditions affecting the land-phase of the hydrologic cycle. For each model element, a range of processes that track the watershed response are calculated, including: (1) canopy interception and evaporation; (2) infiltration, soil moisture redistribution, and runoff generation; (3) evaporation from bare soil and transpiration from vegetation; (4) shallow subsurface flow; and (5) overland and channel flow. The model is also capable of ingesting time-variable vegetation parameters ${ }^{60}$ and the modeling domain can be partitioned into subdomains for parallel computing ${ }^{61}$. 
We briefly describe the infiltration, runoff generation, channel transmission losses, and vegetation representations for dryland systems with shallow soils. Each model element has a heterogeneous, sloped soil column above a semi-impermeable carbonate layer ${ }^{45}$. A modified version of the Green-Ampt equation that represents unsaturated flow in layered soils is used to calculate infiltration ${ }^{58,62}$. Precipitation pulses lead to single infiltration fronts that interact with antecedent soil water to impact runoff generation and subsequent infiltration. Soil water is redistributed laterally based on topographic gradients. Following storm events, soil water is depleted through bare soil evaporation and plant transpiration to meet the atmospheric demand via closing the energy balance using the Penman-Monteith equation ${ }^{58}$. A vegetative fraction for each model element determines the fractions of bare soil evaporation and transpiration and is treated as a species-dependent parameter that varies with observed plant phenology ${ }^{46}$.

tRIBS simulates runoff generation as either Hortonian (infiltration excess) or Dunnian (saturation excess) processes depending on the wetness state in hillslope soils ${ }^{58}$. Groundwater exfiltration and perched return flow can also be simulated, but are not observed in this system ${ }^{46}$. Runoff is transported to the watershed outlet by first routing the runoff along each hillslope in the direction of steepest descent based on the hillslope path length and a velocity dependent on the downstream channel discharge ${ }^{58,62}$. In the channel network, river routing is simulated using a one-dimensional, finite element, kinematic wave approximation using the Manning's equation for rectangular cross sections. Recent modifications to the model allow for channel transmission losses of hillslope-derived runoff that account for the impact of capillary forces on infiltration in ephemeral channels during the initial period of infiltration ${ }^{46}$, termed the transient period. A key limitation of this approach is that this model is not a fully integrated surface water-groundwater model. Therefore, transmission losses that are lost from the model domain cannot be accessed by deep-rooted shrubs. Additionally, all shrubs in the modeling framework have their roots limited to the soil layer $($ top $50 \mathrm{~cm}$ ) and the carbonate layer is treated as a fully impermeable unit. While these assumptions result in a simplified system, in situ observations suggest that they are reasonable approximations and will not significantly alter conclusions drawn from the model ${ }^{37,63}$.

Woody Plant Encroachment Scenarios. This study was performed in a mixed shrubland of the Jornada Experimental Range USDA-LTER site of southern New Mexico ${ }^{45}$. The study watershed has undergone woody plant encroachment since $1850^{43}$ leading to the current state consisting of creosote bush (Larrea tridentata), honey mesquite (Prosopis glandulosa Torr.), several perennial bunchgrass species (Muhlenbergia porteri, Pleuraphis mutica, and Sporobolus cryptandrus), and other shrubs (Parthenium incanum, Flourensia cernua, and Gutierrezia sarothrae). The model was parameterized to ensure accurate representation of shrubs and grasses. When conducting WPE scenarios, however, a generic shrub class was used based upon the time-variable parameters and phenology of mesquite shrubs. No significant differences in the water budget were obtained when a set of mixed shrubs were represented.

To generate the WPE scenarios, we constructed random distributions of shrubs, grasses, and bare soil to meet plant cover specifications (Fig. 1c,d). These were generated within ArcGIS to create spatially distributed raster datasets. Several random realizations of shrub distribution for the same total shrub cover as the current observed state yielded no significant difference in the hydrologic response (Fig. S7). Plant cover specifications were developed to follow the two WPE pathways. Xerification better represents dry conditions at the study site where WPE results in high bare soil cover. To achieve these, we developed relations between aboveground net primary production (ANPP) and plant cover for grasses and shrubs. Total ANPP does not change with WPE ${ }^{64,65}$ in arid environments where xerification occurs, but the relation between biomass and percentage cover is steeper for shrubs than for grasses; thus, to maintain constant ANPP with WPE, there is an increase in bare soil. Thicketization occurs in more humid environments where grasses are replaced by shrubs since there is sufficient precipitation to support increased ANPP (Fig. S8).

Model Scenario Simulations. We performed the hydrologic simulations for a period that corresponds with hydrologic monitoring at the site ${ }^{45}$ : July 1, 2010 - September 30, 2016 (6.25 years), a total of 7 growing seasons (1 July to 1 October). Meteorological forcings consisted of observed values of solar radiation, wind speed, air temperature, relative humidity, and barometric pressure at 30-minute intervals and applied uniformly to the watershed $^{46}$. Precipitation at 30-minute resolution was derived from four rain gauges in the watershed ${ }^{45}$. Simulations were performed with a spatial resolution of $1 \mathrm{~m}$ resulting in $\sim 47,000$ computational elements requiring $25 \mathrm{CPU}$ hours per year of simulation. Parallel computations were used to decrease simulation time based on subdomain partitioning of the channel network into 8 regions ${ }^{61}$. A base case consisting of observed vegetation at the study site was calibrated and validated using extensive observations of soil moisture, streamflow, evapotranspiration, and the energy balance ${ }^{46}$. Static model parameters are presented in Table S1. Vegetation parameters include time variable phenology based on phenocam measurements from the study site ${ }^{46}$. The model outputs of interest are the water budget components of evapotranspiration, streamflow, and transmission losses. Transmission losses are defined as deep percolation in the channel network and can occur even when insufficient streamflow develops to exit the watershed.

Climate change scenarios rely on stochastic downscaling of general circulation models (GCMs) to produce representative realizations of potential future climates in the region ${ }^{66-68}$. This technique applies delta change values to the statistical properties of historical precipitation and air temperature based on the differences between current and future periods. We obtained projections from the Coupled Model Intercomparison Project version 5 for three GCMs shown to be effective for desert regions ${ }^{69}$ : (1) CNRM-CM5, (2) CSIRO Mk3.6.0, and (3) HadGEM2-ES. We selected single realizations from each model that represent a late century (2085-2100) period under the representative concentration pathway (RCP) 8.5. The 15-year period was selected to match the length of a historical period from NLDAS- $2^{70}(1990-2005)$. We used the statistical properties of the 15-year periods to generate hourly forcing data, representative of the three GCMs and the historical conditions, over synthetic 
100-year periods. These forcings should be considered representative realizations of the climate under stationary historical and late century conditions. Due to computational limitations, we selected three WPE scenarios to combine with the climate change cases: (1) 70\% grass (0\% shrub), (2) $0 \%$ grass xerification (35\% shrub), and (3) $0 \%$ grass thicketization $(70 \%$ shrub). Each vegetation state was run with the stochastically generated forcings representing historical conditions and late $21^{\text {st }}$-century conditions. We note that hourly precipitation values suppress finer-scale variations which are important for the short duration, high-intensity events leading to channel transmission losses at the site. Because of this, simulations using the long-term synthetic data are used only to compare the relative importance of WPE and climate change on the dryland water budget.

Received: 16 November 2019; Accepted: 2 April 2020;

Published online: 15 May 2020

\section{References}

1. Asner, G. P. et al. Grazing systems, ecosystem responses and global change. Annual Reviews of Environmental Resources 29, 261-299 (2004).

2. Wilcox, B. P. Transformative ecosystem change and ecohydrology: Ushering in a new era for watershed management. Ecohydrology 3, 120-130 (2010).

3. Van Auken, O. W. Shrub invasions of North American semiarid grasslands. Annual Reviews of Ecological Systems 31, 197-215 (2000).

4. Stevens, N., Lehmann, C. E. R., Murphy, B. P. \& Durigan, G. Savanna woody encroachment is widespread across three continents. Global Change Biology 23, 235-244 (2017).

5. Anadón, J. D., Sala, O. E., Turner, B. L. II \& Bennett, E. M. Effect of woody-plant encroachment on livestock production in North and South America. Proceedings of the National Academy of Sciences 111(35), 12948-12953 (2014).

6. Schooley, R.L., Bestelmeyer, B.T., \& Campanella, A. Shrub encroachment, productivity pulses, and core-transient dynamics of Chihuahuan Desert rodents. Ecosphere 9(7), https://doi.org/10.1002/ecs2.2330, (2018).

7. Huxman, T. E. et al. Ecohydrological implications of woody plant encroachment. Ecology 86(2), 308-319 (2005).

8. Pierini, N.P., Vivoni, E.R., Robles-Morua, A., Scott, R.L., \& Nearing, M.A. Using observations and a distributed hydrologic model to explore runoff thresholds linked with mesquite encroachment in the Sonoran Desert. Water Resources Research 50, https://doi. org/10.1002/2014WR015781 (2014)

9. Breshears, D. D. The grassland-forest continuum: trends in ecosystem properties for woody plant mosaics? Frontiers in Ecology and the Environment 4(2), 96-104 (2006).

10. Acharya, B. et al. Woody plant encroachment alters soil hydrological properties and reduces downward flux of water in tallgrass prairie. Plant Soil 414, 379-391 (2017).

11. Seyfried, M. S. Ecohydrological control of deep drainage in arid and semiarid regions. Ecology 86(2), 277-287 (2005).

12. Sandvig, R.M. \& Phillips, F.M. Ecohydrological controls on soil moisture fluxes in arid to semiarid vadose zones. Water Resources Research 42, https://doi.org/10.1029/2005WR004644 (2006).

13. Wine, M. L., Hendrickx, J. M. H., Cadol, D., Zou, C. B. \& Ochsner, T. E. Deep drainage sensitivity to climate, edaphic factors, and woody encroachment, Oklahoma, USA. Hydrological Processes 29(17), 3779-3789 (2015).

14. Seyfried, M. S. Ecohydrological control of deep drainage in arid and semiarid regions. Ecology 86(2), 277-287 (2005).

15. Ivanov, V.Y., Bras, R.L., \& Vivoni, E.R. Vegetation-hydrology dynamics in complex terrain of semiarid areas: 2. Energy-water controls of vegetation spatiotemporal dynamics and topographic niches of favorability. Water Resources Research 44, https://doi. org/10.1029/2006WR005595, (2008).

16. Bestelmeyer, B. T., Goolsby, D. P. \& Archer, S. R. Spatial perspectives in state-and-transition models: a missing link to land management? Journal of Applied Ecology 48, 746-757 (2011).

17. Zhang, Y. et al. Modeling climate change effects on runoff and soil erosion in southeastern Arizona rangelands and implications for mitigation with conservation practices. Journal of Soil and Water Conservation 67(5), 390-405 (2012).

18. Diffenbaugh, N. S., Swain, D. L. \& Touma, D. Anthropogenic warming has increased drought risk in California. Proceedings of the National Academy of Sciences 112(13), 3931-3936 (2015).

19. Cook, B. I., Smerdon, J. E., Seager, R. \& Coats, S. Global warming and $21^{\text {st }}$ century drying. Climate Dynamics 43, 2607-2627 (2014).

20. Dai, A. Increasing drought under global warming in observations and models. Nature Climate Change 3, 52-58 (2012).

21. Pascale, S. et al. Weakening of the North American monsoon with global warming. Nature Climate Change 7, 807-812 (2017),

22. Garfin, G., Jardine, A., Merideth, R., Black, M., \& Leroy, S. Eds., Assessment of climate change in the southwest United States: A report prepared for the national climate change assessment. Island Press, $531 \mathrm{pp}$. (2013).

23. Melillo, J.M., Richmond, T.T. \& Yohe, G. Climate change impacts in the United States Third National Climate Assessment (Washington, DC: US Global Change Research Program), (2014).

24. McKenna, O.P. \& Sala, O.E. Groundwater recharge in desert playas: current rates and future effects of climate change. Environmental Research Letters 13, https://doi.org/10.1088/1748-9326/aa9eb6

25. Cook, B. I. \& Seager, R. The response of the North American Monsoon to increased greenhouse gas forcing. Journal of Geophysical Research: Atmospheres 118, 1690-1999 (2013).

26. Luong, T. M. et al. The more extreme nature of North American monsoon precipitation in the southwestern United States as revealed by a historical climatology of simulated severe weather events. Journal of Applied Meteorology and Climatology 56, 2509-2529 (2017).

27. Pool, D. R. \& Dickinson, J. E. Ground-water flow model of the Sierra Vista subwatershed and Sonoran portions of the Upper San Pedro Basin, southeastern Arizona, United States, and Northern Sonora, Mexico. U.S. Department of the Interior, U.S. Geological Survey, Reston, VA: Prepared in cooperation with the Upper San Pedro Partnership and Bureau of Land Management, (2007).

28. Wilson, J. L. \& Guan, H. Mountain-block hydrology and mountain-front recharge. Pages 113-135 in Hogan, J.F., Phillips, F.M., \& Scanlon, B.R., editors. Groundwater Recharge in a Desert Environment. American Geophysical Union, Washington, D.C., USA (2004).

29. Archer, S., Boutton, T.W., \& Hibbard, K.A. Trees in grasslands: biogeochemical consequences of woody plant expansion, pages 115-137 in Global Biogeochemical Cycles in the Climate System, Schulze, E. D. et al., editors. Academic Press, San Diego, (2000).

30. Okin, G. S., Herrick, J. E. \& Gillette, D. A. Multiscale controls on and consequences of Aeolian processes in landscape change in arid and semiarid environments. Journal of Arid Environments 65, 253-275 (2006).

31. Mueller, E. N., Wainwright, J. \& Parsons, A. J. Impact of connectivity on the modeling of overland flow within semiarid shrubland environments. Water Resources Research 43, W09412 (2007).

32. Brown, J. H., Valone, T. J. \& Curtin, C. G. Reorganization of an arid ecosystem in response to recent climate change. Proceedings of the National Academy of Sciences 94(18), 9729-9733 (1997).

33. Gibbens, R. P., Beck, R. F., McNeely, R. P. \& Herbel, C. H. Recent rates of mesquite establishment on the northern Chihuahuan Desert. Journal of Range Management 45, 585-588 (1992). 
34. Archer, S. Have southern Texas savannas been converted to woodlands in recent history? The American Naturalist 134(4), 545-561 (1989).

35. Boutton, T. W., Archer, S., Midwood, A. J., Zitzer, S. F. \& Bol, R. ${ }^{13} \mathrm{C}$ values of soil organic carbon and their use in documenting vegetation change in a subtropical savanna ecosystem. Geoderma 82(1-3), 5-41 (1998).

36. Puigdefábregas, J. The role of vegetation patterns in structuring runoff and sediment fluxes in drylands. Earth Surface Processes and Landforms 30(2), 133-147 (2005).

37. Schreiner-McGraw, A.P., \& Vivoni, E.R. Percolation observations in an arid piedmont watershed and linkages to historical conditions in the Chihuahuan Desert. Ecosphere 8(11), https://doi.org/10.1002/ecs2.2000, (2017).

38. Goodrich, D. C., Kepner, W. G., Levick, L. R. \& Wigington, P. J. Jr. Southwestern intermittent and ephemeral stream connectivity. Journal of the American Water Resources Association 54(2), 400-422 (2018).

39. Archer, S.R. et al. Woody plant encroachment: Causes and consequences. Pages 25-84 in Briske, D. D., ed. Rangeland Systems. Springer Series on Environmental Management, Springer, Cham. (2017).

40. Venter, Z. S., Cramer, M. D. \& Hawkins, H. J. Drivers of woody plant encroachment over Africa. Nature Communications 9,2272 (2018).

41. Rosan, T. M. et al. Extensive $21^{\text {st }}$-century woody encroachment in South America's savanna. Geophysical Research Letters 46, 6594-6603 (2019).

42. Peng, H.-Y. et al. Shrub encroachment with increasing anthropogenic disturbance in the semiarid Inner Mongolian grasslands of China. Catena 109, 39-48 (2013).

43. Gibbens, R. P., McNeely, R. P., Havstad, K. M., Beck, R. F. \& Nolen, B. Vegetation changes in the Jornada Basin from 1858 to 1998. Journal of Arid Environments 61, 651-668 (2005).

44. Schlesinger, W. H. et al. Biological feedbacks in global desertification. Science 247, 1043-1048 (1990).

45. Templeton, R. C. et al. High-resolution characterization of a semiarid watershed: Implications on evapotranspiration estimates. Journal of Hydrology 509, 306-319 (2014).

46. Schreiner-McGraw, A.P. \& Vivoni, E.R. On the sensitivity of hillslope runoff and channel transmission losses in arid piedmont slopes. Water Resources Research 54, https://doi.org/10.1029/2018WR022842 (2018).

47. Eldridge, D. J., Wang, L. \& Ruiz-Colmenero, M. Shrub encroachment alters the spatial patterns of infiltration. Ecohydrology 8, 83-93 (2015).

48. Wilcox, B. P., Wood, M. K. \& Tromble, J. M. Factors influencing infiltrability of semiarid mountain slopes. Journal of Range Management 41(3), 197-206 (1988).

49. Turnbull, L., Wainwright, J. \& Brazier, R. E. A conceptual framework for understanding semi-arid land degradation: ecohydrological interactions across multiple-space and time scales. Ecohydrology 1, 23-34 (2008).

50. Wainwright, J., Parsons, A. J. \& Abrahams, A. D. Plot-scale studies of vegetation, overland flow and erosion interactions: case studies from Arizona and New Mexico. Hydrological Processes 14, 2921-2943 (2000).

51. Blasch, K.W., Ferré, T.P.A., Hoffmann, J.P., \& Fleming, J.B. Relative contributions of transient and steady state infiltration during ephemeral streamflow. Water Resources Research 42, https://doi.org/10.1029/2005WR004049 (2006).

52. Mueller, E.N., Wainwright, J. \& Parsons, A.J. Impact of connectivity on the modeling of overland flow within semiarid shrubland environments. Water Resources Research 43, https://doi.org/10.1029/2006WR005006 (2007).

53. Lebron, I. et al. Ecohydrological controls on soil moisture and hydraulic conductivity within a pinyon-juniper woodland. Water Resources Research 43(8), https://doi.org/10.1029/2006WR005398, (2007).

54. Schreiner-McGraw, A. P. Deep percolation in arid piedmont watersheds and its sensitivity to ecosystem change. (Arizona State University, 2017).

55. Schreiner-McGraw, A. P., Ajami, H. \& Vivoni, E. R. Extreme weather events and transmission losses in arid streams. Environmental Research Letters 14, 084002 (2019).

56. Gherardi, L. A. \& Sala, O. E. Enhanced precipitation variability decreases grass- and increases shrub-productivity. Proceedings of the National Academy of Sciences 112(41), 12735-12740 (2015).

57. Pierce, N., Archer, S. R., Bestelmeyer, B. T. \& James, D. K. Grass-shrub competition in arid lands: an overlooked driver in grasslandshrubland state transitions? Ecosystems 21, 1-10 (2018).

58. Ivanov, V.Y., Vivoni, E.R., Bras, R.L., \& Entekhabi, D. Catchment hydrologic response with a fully-distributed triangulated irregular network model. Water Resources Research 40, https://doi.org/10.1029/2004WR003218, (2004).

59. Vivoni, E. R., Entekhabi, D., Bras, R. L. \& Ivanov, V. Y. Controls on runoff generation and scale-dependence in a distributed hydrologic model. Hydrology and Earth System Sciences 11(5), 1683-1701 (2007).

60. Vivoni, E. R. Spatial patterns, processes and predictions in ecohydrology: Integrating technologies to meet the challenge. Ecohydrology 5, 235-241 (2012).

61. Vivoni, E. R. et al. Real-world hydrologic assessment of a fully-distributed hydrological model in a parallel computing environment. Journal of Hydrology 409, 483-496 (2011).

62. Garrote, L. \& Bras, R. L. A distributed model for real-time flood forecasting using digital elevation models. Journal of Hydrology 167, 279-306 (1995)

63. Dunniway, M. C., Snyder, K. A. \& Herrick, J. E. Spatial and temporal patterns of water availability in a grass-shrub ecotone and implications for grassland recovery in arid environments. Ecohydrology 3, 55-67 (2010).

64. Knapp, A. K. et al. Shrub encroachment in North American grasslands: shifts in growth form dominance rapidly alters control of ecosystem carbon inputs. Global Change Biology 14, 615-623 (2008).

65. Flombaum, P. \& Sala, O. E. A non-destructive and rapid method to estimate biomass and aboveground net primary production in arid environments. Journal of Arid Environments 69, 352-358 (2007).

66. Fatichi, S., Ivanov, V. Y. \& Caporali, E. Simulation of future climate scenarios with a weather generator. Advances in Water Resources 34(4), 448-467 (2011).

67. Fatichi, S., Ivanov, V. Y. \& Caporali, E. Assessment of a stochastic downscaling methodology in generating an ensemble of hourly future climate time series. Climate Dynamics 40(7-8), 1841-1861 (2013).

68. Verduzco, V. S. et al. Climate change impacts on net ecosystem productivity in a subtropical shrubland of Northwestern Mexico. Journal of Geophysical Research: Biogeosciences 123(2), 688-711 (2018).

69. Geil, K. L., Serra, Y. L. \& Zeng, X. Assessment of CMIP5 model simulations of the North American monsoon system. Journal of Climate 26(22), 8787-8801 (2013).

70. Xia, R. et al. Continental-scale water and energy flux analysis and validation for the North American Land Data Assimilation System project phase 2 (NLDAS-2): 1. Intercomparison and application of model products. Journal of Geophysical Research 117, https://doi. org/10.1029/2011JD016048, (2012)

\section{Acknowledgements}

Funding provided by the Jornada LTER (DEB-1235828/DEB 18-32194), USDA AFRI (2016-67013-24932), UC Riverside Agricultural Experiment Station Mission Fund, and USDA NIFA Graduate Fellowship program (201767011-26069) to A.S-M. is acknowledged. Datasets for the site are available at the Jornada Data Catalog (http:// jornada.nmsu.edu/lter/data). 


\section{Author contributions}

A.S.-M. and E.V. designed the experiment. A.S.-M. performed the simulations, data analysis, and wrote the first draft of the manuscript. H.A. and E.V. contributed to writing the manuscript. O.S., H.T. and D.P. contributed ideas to the experimental design and reviewed the manuscript.

\section{Competing interests}

The authors declare no competing interests.

\section{Additional information}

Supplementary information is available for this paper at https://doi.org/10.1038/s41598-020-65094-x.

Correspondence and requests for materials should be addressed to A.P.S.-M.

Reprints and permissions information is available at www.nature.com/reprints.

Publisher's note Springer Nature remains neutral with regard to jurisdictional claims in published maps and institutional affiliations.

(c) (1) Open Access This article is licensed under a Creative Commons Attribution 4.0 International License, which permits use, sharing, adaptation, distribution and reproduction in any medium or format, as long as you give appropriate credit to the original author(s) and the source, provide a link to the Creative Commons license, and indicate if changes were made. The images or other third party material in this article are included in the article's Creative Commons license, unless indicated otherwise in a credit line to the material. If material is not included in the article's Creative Commons license and your intended use is not permitted by statutory regulation or exceeds the permitted use, you will need to obtain permission directly from the copyright holder. To view a copy of this license, visit http://creativecommons.org/licenses/by/4.0/.

(C) The Author(s) 2020 